\title{
An Algorithm for Evaluation of Lightning Electromagnetic Fields at Different Distances with respect to Lightning Channel
}

\author{
Mahdi Izadi, ${ }^{1,2}$ Mohd Zainal Abidin Ab Kadir, ${ }^{1}$ and Maryam Hajikhani ${ }^{3}$ \\ ${ }^{1}$ Centre for Electromagnetic and Lightning Protection Research (CELP), Faculty of Engineering, Universiti Putra Malaysia, \\ 43400 Serdang, Selangor, Malaysia \\ ${ }^{2}$ Islamic Azad University, Firoozkooh Branch, Iran \\ ${ }^{3}$ Aryaphase Company, Tehran, Iran
}

Correspondence should be addressed to Mahdi Izadi; aryaphase@yahoo.com

Received 9 September 2014; Accepted 23 October 2014; Published 12 November 2014

Academic Editor: Chien-Yu Lu

Copyright (C) 2014 Mahdi Izadi et al. This is an open access article distributed under the Creative Commons Attribution License, which permits unrestricted use, distribution, and reproduction in any medium, provided the original work is properly cited.

\begin{abstract}
The analytical field expressions are proposed to estimate the electromagnetic fields associated with vertical lightning channel at an observation point directly in the time domain using current and geometrical parameters. The proposed expressions embrace a large number of channel base current functions and widely used engineering current models. Moreover, they can be joined with different coupling models for evaluation of lightning induced voltage when they provide different required field components directly in the time domain. The data from measured fields and simulated fields from previous works were employed to validate the proposed field expressions. The simulated results were compatible with both computed field values from previous studies and the measured fields.
\end{abstract}

\section{Introduction}

Lightning is a natural phenomenon that can give effect on the power lines in two ways, that is, direct and indirect. In the direct effects, lightning strikes to power lines or towers or substations directly. On the other hand, the indirect effect considers electromagnetic fields associated with lightning channel and induced voltage due to coupling between generated electromagnetic fields and power system when lightning strikes to the ground or any objective near to power lines or substations $[1,2]$. This study considers the evaluation of electromagnetic fields due to lightning channel. Several methods consider the calculation of electromagnetic fields due to lightning channel while they are validated using measured fields at one or a number of observation points [1] while the most common calculation methods can be concluded by

(i) the MONOPOLE method $[3,4]$,

(ii) the DIPOLE method $[1,3]$, (iii) the FDTD method [5],

(iv) the FDTD-HYBRID methods $[6,7]$.

It should be mentioned that the electromagnetic fields associated with the lightning channel rely basically on some geometrical, channel, and ground parameters. The basic input parameters in almost all calculation methods in perfect ground conductivity case are

(i) the channel base current that is usually prepared with direct measurement [2] from the triggered lightning technique or obtained from inverse procedure algorithms from measured electromagnetic fields $[8,9]$,

(ii) the current model for prediction of return stroke current wave shape along lightning channel,

(iii) the radial distance from lightning channel,

(iv) the observation point height with respect to ground surface,

(v) the return stroke current velocity along lightning channel. 
TABLE 1: The widely used channel base current functions.

\begin{tabular}{|c|c|}
\hline Current model & Channel base current function \\
\hline Bruce and Golde [29] & $I_{p}[\exp (-A t)-\exp (-B t)]$ \\
\hline $\begin{array}{l}\text { Improvement of Uman and McLain on Bruce and } \\
\text { Golde function [30] }\end{array}$ & $\frac{I_{p}}{\eta}[\exp (-A t)-\exp (-B t)]$ \\
\hline Improvement of Jones on Bruce and Golde function [31] & $\begin{array}{c}\frac{I_{p}}{\eta}\left[\exp \left(-\frac{t^{*}}{\Gamma_{1}}\right)-\exp \left(-\frac{t^{*}}{\Gamma_{2}}\right)\right] \\
t^{*}=\frac{\Gamma_{2}^{2}}{\Gamma_{1}}+t\end{array}$ \\
\hline Pierce and Ciones [32] & $I_{p 1}\left[\exp \left(-A_{1} t\right)-\exp \left(-B_{1} t\right)\right]+I_{p 2}\left[\exp \left(-A_{2} t\right)-\exp \left(-B_{2} t\right)\right]$ \\
\hline Heidler function [33] & $\frac{I_{p}}{\eta_{1}} \frac{\left(t / \Gamma_{1}\right)^{n_{1}}}{1+\left(t / \Gamma_{1}\right)^{n_{1}}} \exp \left(\frac{-t}{\Gamma_{2}}\right)$ \\
\hline Sum of two Heidler functions $[11,34]$ & $\frac{i_{01}}{\eta_{1}} \frac{\left(t / \Gamma_{11}\right)^{n_{1}}}{1+\left(t / \Gamma_{11}\right)^{n_{1}}} \exp \left(\frac{-t}{\Gamma_{12}}\right)+\frac{i_{02}}{\eta_{2}} \frac{\left(t / \Gamma_{21}\right)^{n_{2}}}{1+\left(t / \Gamma_{21}\right)^{n_{2}}} \exp \left(\frac{-t}{\Gamma_{22}}\right)$ \\
\hline Improvement of Nucci on Heidler function [35] & $\frac{i_{01}}{\eta_{1}} \frac{\left(t / \Gamma_{11}\right)^{n_{1}}}{1+\left(t / \Gamma_{11}\right)^{n_{1}}} \exp \left(\frac{-t}{\Gamma_{12}}\right)+i_{02}\left[\exp \left(-\Gamma_{21} t\right)-\exp \left(-\Gamma_{22} t\right)\right]$ \\
\hline
\end{tabular}

Two first calculation methods are expressed in the cylindrical [1] and spherical [3, 4] domains using current and charge density [4] parameters along the lightning channel while they have complexity in the calculation of induction partial when some realistic channel base current functions are used (as Heidler function) and they do not have an analytical solution of integral to time $[7,10]$. On the other hand, the FDTD method just is validated for closed distances from lightning channel [5]. Moreover, the FDTD_HYBRID methods need to estimate magnetic fields at six points around observation point for calculation of electric fields at an observation point $[6,7,11]$. In order to provide the general analytical electromagnetic field expressions in the time domain, the widely used channel base current functions are introduced and categorized. Therefore, after generalization of current functions based on proposed expressions, the general electromagnetic field expressions due to vertical lightning channel on the prefect ground are proposed. These equations can be applied to a large number of leading current functions and their combinations and can support different generalized engineering current models directly in the time domain. The basic assumptions of this study are the following.

(i) The ground conductivity is infinite.

(ii) The ground surface is flat.

(iii) The lightning channel is perpendicular to the ground and has no branches.

(iv) The corona effect is negligible.

In the next section, the widely used current functions and current models are reviewed. Therefore, the proposed electromagnetic field expressions are presented. Finally, a justification of the proposed method and its validation by measuring fields and simulated fields from previous studies is given.

\section{Channel Base Current Functions}

Previous studies presented several channel base current functions to simulate return stroke current wave shape at channel base on the ground surface where the fixed coefficients of the current functions were determined by the data from measured current or measured fields using inverse procedure algorithms. The significant channel base current functions are tabulated in Table 1 where $A, A_{1}, A_{2}, B, B_{1}, B_{2}, \Gamma_{1}$, $\Gamma_{2}, \Gamma_{11}, \Gamma_{12}, \Gamma_{21}, \Gamma_{22}, \eta, n_{1}, n_{2}$ are constant coefficients and $I_{p}, I_{p 1}, I_{p 2}, I_{01}, I_{02}$ are current peaks. Note that similar symbols in different current functions do not have a similar concept.

Different channel base current functions in Table 1 can be determined from (1) and (2) by changing the constant coefficients or the combination of (1) and (2). Hence, this study adapts these two basic equations and considers the widely used current functions using a combination of them:

$$
\begin{gathered}
I(0, t)=\frac{I_{0}}{\eta_{0}}\left(c_{1} e^{-\alpha t}-c_{2} e^{-\gamma t}\right), \\
I(0, t)=\frac{I_{01}}{\eta_{01}} \frac{\left(t / t_{1}\right)^{n}}{1+\left(t / t_{1}\right)^{n}} \exp \left(\frac{-t}{t_{2}}\right),
\end{gathered}
$$

where

$$
\eta_{01}=\exp \left[-\left(\frac{t_{1}}{t_{2}}\right)\left(n \frac{t_{2}}{t_{1}}\right)^{1 / n}\right]
$$

\section{Return Stroke Current Models}

One of the effective factors on electromagnetic field calculations is the behavior of return stroke currents at different heights along the lightning channel that is modeled via 
TABLE 2: The internal parameters of (4) for different engineering models [12].

\begin{tabular}{lcc}
\hline Model & $P\left(z^{\prime}\right)$ & $v$ \\
\hline $\begin{array}{l}\text { Bruce and Golde (BG) [29] } \\
\text { Traveling Current Source (TCS) }\end{array}$ & 1 & $\infty$ \\
{$[36]$} & 1 & $-c$ \\
Transmission Line (TL) [1] & 1 & $v_{f}$ \\
$\begin{array}{l}\text { Modified Transmission Line with } \\
\text { Linear Decay (MTLL) [1] }\end{array}$ & $\left(1-\frac{z^{\prime}}{H_{c}}\right)$ & $v_{f}$ \\
$\begin{array}{l}\text { Modified Transmission Line with } \\
\text { Exponential Decay (MTLE) [1] }\end{array}$ & $\exp \left(-\frac{z^{\prime}}{\lambda}\right)$ & $v_{f}$ \\
\hline
\end{tabular}

current models. Generally, the return stroke current models can be classified into four groups as follows $[12,13]$ :

(i) the gas-dynamic or physical models,

(ii) the current distributed models,

(iii) the electromagnetic models,

(iv) the engineering models.

To develop general expressions for electromagnetic fields due to lightning channel, the engineering models are applied in this study. In the engineering models, the current at different heights along the lightning channel can be expressed by a special function based on the channel base current and an attenuation height dependent factor. Most of the engineering models can be presented by a general equation such as $(4)[12,13]$. The internal parameters of $(4)$ for different engineering current models are listed in Table $2[1,12]$ where $c$ is considered as the speed of light in free space, $\lambda$ as a decay constant (1 2 km), and $H_{c}$ as the cloud height with respect to the ground surface [1]:

$$
I\left(z^{\prime}, t\right)=I\left(0, t-\frac{z^{\prime}}{v}\right) \times P\left(z^{\prime}\right) \times u\left(t-\frac{z^{\prime}}{v_{f}}\right),
$$

where $z^{\prime}$ is the temporary charge height along lightning channel, $I\left(z^{\prime}, t\right)$ is current distribution along the lightning channel at any height $z^{\prime}$ and any time $t, I(0, t)$ is channel base current, $P\left(z^{\prime}\right)$ is the attenuation height dependent factor, $v$ is the current-wave propagation velocity, $v_{f}$ is the upward propagating front velocity, and $u$ is the Heaviside function defended as

$$
u\left(t-\frac{z^{\prime}}{v_{f}}\right)=\left\{\begin{array}{lr}
1 & \text { for } t \geq \frac{z^{\prime}}{v_{f}} \\
0 & \text { for } t<\frac{z^{\prime}}{v_{f}} .
\end{array}\right.
$$

Based on (4), return stroke current at the height of $z^{\prime}$ along the lightning channel can be estimated by using channel base current and the height dependent attenuation factor.

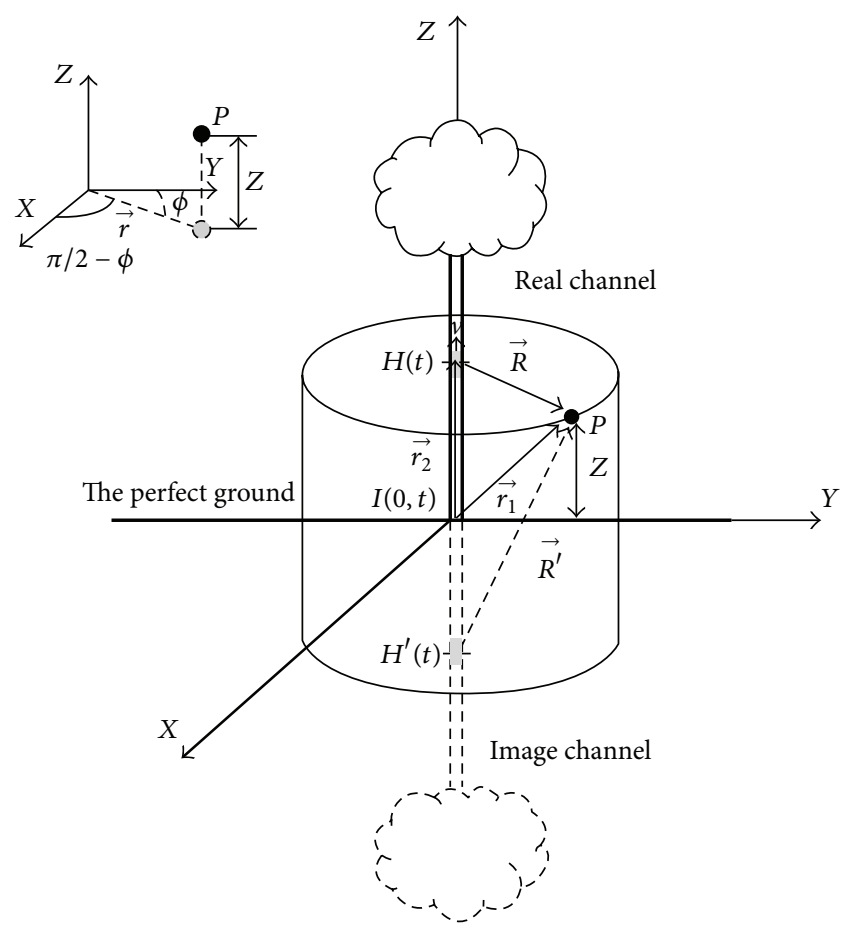

FIGURE 1: Geometry of the problem.

Note that, in recent years, several models based on (4) and using measured electromagnetic fields and inverse procedure algorithms were presented [14-16]. Similarly, different current models can be examined by the comparison between simulated electromagnetic fields using current model and measured fields at different observation points [1]. In this model the assumed return stroke velocity is set at a constant value that is typically between $c / 2$ and $2 c / 3$ [17].

\section{Electromagnetic Fields Associated with Lightning Channel}

In this section, electromagnetic field expressions due to two expressed functions in (1) and (2) at an observation point above the ground surface are estimated whereas the current model is set on (4). According to the geometry of the situation (see Figure 1 ), the potential vector $(\vec{A})$ at the observation point above ground surface can be obtained from (6) when Maxwell's equation $[3,18]$ and Lorentz gauge [19] are applied:

$$
\nabla^{2} \vec{A}-\mu_{0} \varepsilon_{0} \frac{\partial^{2} \vec{A}}{\partial t^{2}}=-\mu_{0} \vec{J}
$$

where $\vec{J}$ is the current density, $\mu_{0}=4 \pi \times 10^{-7} \mathrm{~V} \cdot \mathrm{s} /(\mathrm{A} \cdot \mathrm{m})$, and $\varepsilon_{0}=8.85 \times 10^{-12} \mathrm{~F} / \mathrm{m}$.

Moreover, Figure 1 demonstrates that the solution to (6) can be obtained from (7) whereas the infinitesimal current source is located along $z$-axis at space in position $\overrightarrow{r_{2}}$ from the origin. Also, the observation point is located at space and $\overrightarrow{r_{1}}$ 
from the origin point; therefore, $\vec{R}$ can be estimated by $\vec{R}=$ $\overrightarrow{r_{1}}-\overrightarrow{r_{2}}$ :

$$
d \vec{A}=\frac{\mu_{0}[\vec{I}] d L^{\prime}}{4 \pi\left|\overrightarrow{r_{1}}-\overrightarrow{r_{2}}\right|},
$$

where $\vec{I}$ is line current density and $d L^{\prime}$ is unit vector along lightning channel.

Likewise, by replacing return stroke current and $d z^{\prime}$ with $\vec{I}$ and unit vector, respectively, in (7) can convert it to (8)

$$
\overrightarrow{d A_{z}}=\frac{\mu_{0} i\left(z^{\prime}, t-(R / c)\right) d z^{\prime}}{4 \pi R}
$$

where

$$
\begin{gathered}
r=\sqrt{x^{2}+y^{2}} \\
R=\sqrt{x^{2}+y^{2}+\left(z-z^{\prime}\right)^{2}} .
\end{gathered}
$$

Further, the magnetic flux density and electric fields can be obtained from potential vector $\vec{A}$ as expressed in (10) and (11), respectively $[3,18]$ :

$$
\begin{gathered}
\vec{B}=\nabla \times \vec{A} \\
\nabla \times \vec{E}=-\frac{\partial \vec{B}}{\partial t}=-\frac{\partial(\nabla \times \vec{A})}{\partial t},
\end{gathered}
$$

where $\vec{B}$ is the magnetic flux density and $\vec{E}$ is the electric field vector.

Therefore, based on the general current model in (4), the field components for first current function as presented in (1) can be obtained from (12), when (8), (10), (11), the trapezoid, and FDTD methods are applied [20-22]. Note that the internal parameters are collected from Table 3. Also, $\vec{B}_{z \_\mathrm{RS} 1}\left(x, y, z, t_{n}\right)=0$ :

$$
\begin{gathered}
\vec{B}_{x_{-} \mathrm{RS} 1}\left(x, y, z, t_{n}\right) \\
=\sum_{i=1}^{n} \sum_{m=1}^{k+1}\left\{a_{m} F_{1}\left(x, y, z, t=t_{n}, z^{\prime}=h_{m, i}\right)\right. \\
\left.\quad-a_{m}^{\prime} F_{1}\left(x, y, z, t=t_{n}, z^{\prime}=h_{m, i}^{\prime}\right)\right\}, \\
\vec{B}_{y_{-} \mathrm{RS} 1}\left(x, y, z, t_{n}\right) \\
=\sum_{i=1}^{n} \sum_{m=1}^{k+1}\left(\frac{-x}{y}\right)\left\{a_{m} F_{1}\left(x, y, z, t=t_{n}, z^{\prime}=h_{m, i}\right)\right. \\
\left.\quad-a_{m}^{\prime} F_{1}\left(x, y, z, t=t_{n}, z^{\prime}=h_{m, i}^{\prime}\right)\right\},
\end{gathered}
$$

$$
\begin{aligned}
\vec{E}_{x_{\_} \mathrm{RS} 1}\left(x, y, z, t_{n}\right) & \\
= & \vec{E}_{x_{-} \mathrm{RS} 1}\left(x, y, z, t_{n-1}\right)+\Delta t \\
& \times \sum_{i=1}^{n} \sum_{m=1}^{k+1}\left\{a_{m} F_{2}\left(x, y, z, t=t_{n}, z^{\prime}=h_{m, i}\right)\right. \\
& \left.-a_{m}^{\prime} F_{2}\left(x, y, z, t=t_{n}, z^{\prime}=h_{m, i}^{\prime}\right)\right\}, \\
\vec{E}_{y_{-} \mathrm{RS} 1} & \left(x, y, z, t_{n}\right) \\
= & \vec{E}_{y \_\mathrm{RS} 1}\left(x, y, z, t_{n-1}\right)+\Delta t \\
& \times \sum_{i=1}^{n} \sum_{m=1}^{k+1}\left(\frac{y}{x}\right)\left\{a_{m} F_{2}\left(x, y, z, t=t_{n}, z^{\prime}=h_{m, i}\right)\right. \\
\vec{E}_{z \_\mathrm{RS} 1} & \left(x, y, z, t_{n}\right) \\
= & \vec{E}_{z \_\mathrm{RS} 1}\left(x, y, z, t_{n-1}\right)+\Delta t \\
& \times \sum_{i=1}^{n} \sum_{m=1}^{k+1}\left\{a_{m} F_{3}\left(x, y, z, t=t_{n}, z^{\prime}=h_{m, i}\right)\right. \\
\left.-a_{m}^{\prime} F_{3}\left(x, y, z, t=t_{n}, z^{\prime}=h_{m, i}^{\prime}\right)\right\}, &
\end{aligned}
$$

where $\vec{B}_{x_{-} \mathrm{RS} 1}$ is the magnetic flux density at $x$-axis due to return stroke current function from (1), $\vec{B}_{y_{-} \mathrm{RS} 1}$ is the magnetic flux density at $y$-axis due to return stroke current function from (1), $\vec{B}_{z \_ \text {RS1 }}$ is the magnetic flux density at $z$-axis due to return stroke current function from (1), $\vec{E}_{x_{-} \mathrm{RS} 1}$ is the electric field at $x$-axis due to return stroke current function from (1), $\vec{E}_{y \_ \text {RS1 }}$ is the electric field at $y$-axis due to return stroke current function from (1), and $\vec{E}_{z \_ \text {RS1 }}$ is the electric field at $z$-axis due to return stroke current function from (1). $\Delta t$ is the time step, $n$ is the number of time steps,

$$
\begin{gathered}
t_{n}=\frac{\sqrt{r^{2}+z^{2}}}{c}+(n-1) \Delta t \quad n=1,2, \ldots, n_{\max } \\
a_{m}= \begin{cases}\frac{\Delta h_{i}}{2 \times k} & \text { for } m=1, m=k+1 \\
\frac{\Delta h_{i}}{k} & \text { for others }\end{cases} \\
a_{m}^{\prime}= \begin{cases}\frac{\Delta h_{i}^{\prime}}{2 \times k} & \text { for } m=1, m=k+1 \\
\frac{\Delta h_{i}^{\prime}}{k} & \text { for others, }\end{cases}
\end{gathered}
$$




$$
\begin{aligned}
& \Delta h_{i}=\left\{\begin{array}{l}
\beta \chi^{2}\left\{\left(c t_{i}-c t_{i-1}\right)-\sqrt{\left(\beta c t_{i}-z\right)^{2}+\left(\frac{r}{\chi}\right)^{2}}+\sqrt{\left(\beta c t_{i-1}-z\right)^{2}+\left(\frac{r}{\chi}\right)^{2}}\right\} \\
\beta \chi^{2}\left\{-\left(\beta z-c t_{i}\right)-\sqrt{\left(\beta c t_{i}-z\right)^{2}+\left(\frac{r}{\chi}\right)^{2}}\right\} \quad \text { for } i=1
\end{array}\right. \\
& \Delta h_{i}^{\prime}=\left\{\begin{array}{l}
\beta \chi^{2}\left\{\left(c t_{i-1}-c t_{i}\right)+\sqrt{\left(\beta c t_{i}+z\right)^{2}+\left(\frac{r}{\chi}\right)^{2}}-\sqrt{\left(\beta c t_{i-1}+z\right)^{2}+\left(\frac{r}{\chi}\right)^{2}}\right\} \\
\beta \chi^{2}\left\{-\left(\beta z+c t_{i}\right)+\sqrt{\left(\beta c t_{i}+z\right)^{2}+\left(\frac{r}{\chi}\right)^{2}}\right\} \quad \text { for } i=1
\end{array}\right.
\end{aligned}
$$

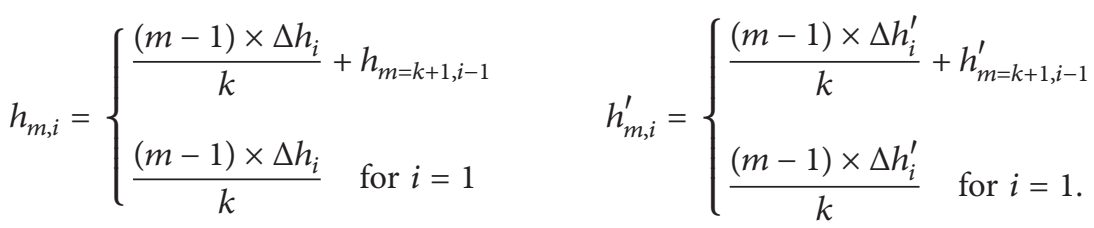

In addition, by using the same methodology that was used for the first current function, the components of electromagnetic field for the second current function as expressed in (2) are proposed by (15). Note that $\vec{B}_{z \_\mathrm{RS} 2}\left(x, y, z, t_{n}\right)=0$ :

$$
\begin{aligned}
& \vec{B}_{x_{-} \mathrm{RS} 2}\left(x, y, z, t_{n}\right) \\
& =\sum_{i=1}^{n} \sum_{m=1}^{k+1}\left\{a_{m} F_{4}\left(x, y, z, t=t_{n}, z^{\prime}=h_{m, i}\right)\right. \\
& \left.-a_{m}^{\prime} F_{4}\left(x, y, z, t=t_{n}, z^{\prime}=h_{m, i}^{\prime}\right)\right\}, \\
& \vec{B}_{y_{-} \mathrm{RS} 2}\left(x, y, z, t_{n}\right) \\
& \begin{aligned}
=\sum_{i=1}^{n} \sum_{m=1}^{k+1}\left(\frac{-x}{y}\right)\{ & a_{m} F_{4}\left(x, y, z, t=t_{n}, z^{\prime}=h_{m, i}\right) \\
& \left.-a_{m}^{\prime} F_{4}\left(x, y, z, t=t_{n}, z^{\prime}=h_{m, i}^{\prime}\right)\right\},
\end{aligned} \\
& \vec{E}_{x_{-} \mathrm{RS} 2}\left(x, y, z, t_{n}\right) \\
& =\vec{E}_{x_{-} \mathrm{RS} 2}\left(x, y, z, t_{n-1}\right)+\Delta t \\
& \times \sum_{i=1}^{n} \sum_{m=1}^{k+1}\left\{a_{m} F_{5}\left(x, y, z, t=t_{n}, z^{\prime}=h_{m, i}\right)\right. \\
& \left.-a_{m}^{\prime} F_{5}\left(x, y, z, t=t_{n}, z^{\prime}=h_{m, i}^{\prime}\right)\right\}, \\
& \vec{E}_{y_{-} \mathrm{RS} 2}\left(x, y, z, t_{n}\right) \\
& =\vec{E}_{y_{-} \mathrm{RS} 2}\left(x, y, z, t_{n-1}\right)+\Delta t \\
& \times \sum_{i=1}^{n} \sum_{m=1}^{k+1}\left(\frac{y}{x}\right)\left\{a_{m} F_{5}\left(x, y, z, t=t_{n}, z^{\prime}=h_{m, i}\right)\right.
\end{aligned}
$$

$$
\begin{gathered}
\left.-a_{m}^{\prime} F_{5}\left(x, y, z, t=t_{n}, z^{\prime}=h_{m, i}^{\prime}\right)\right\}, \\
\vec{E}_{z \_\mathrm{RS} 2}\left(x, y, z, t_{n}\right) \\
=\vec{E}_{z \_\mathrm{RS} 2}\left(x, y, z, t_{n-1}\right)+\Delta t \\
\times \sum_{i=1}^{n} \sum_{m=1}^{k+1}\left\{a_{m} F_{6}\left(x, y, z, t=t_{n}, z^{\prime}=h_{m, i}\right)\right. \\
\left.\quad-a_{m}^{\prime} F_{6}\left(x, y, z, t=t_{n}, z^{\prime}=h_{m, i}^{\prime}\right)\right\},
\end{gathered}
$$

where $\vec{B}_{x-\mathrm{RS} 2}$ is the magnetic flux density at $x$-axis due to return stroke current function from (2), $\vec{B}_{y_{-} \text {RS2 }}$ is the magnetic flux density at $y$-axis due to return stroke current function from (2), $\vec{B}_{z \_ \text {RS2 }}$ is the magnetic flux density at $z$-axis due to return stroke current function from (2), $\vec{E}_{x_{-} \mathrm{RS} 2}$ is the electric field at $x$-axis due to return stroke current function from (2), $\vec{E}_{y_{-} \mathrm{RS} 2}$ is the electric field at $y$-axis due to return stroke current function from (2), and $\vec{E}_{z \_ \text {RS2 }}$ is the electric field at $z$-axis due to return stroke current function from (2).

Consequently, due to the whole return stroke current functions from Table 1, the electromagnetic fields can be easily estimated via the proposed field expressions whereas the total fields due to two part functions are equal to the sum of the electromagnetic fields due to each part independently. On top of that the first part current functions in Table 3 should be converted to either (1) or (2) format before getting into proposed expressions. In other words, the proposed algorithm can support the whole current models related to (4). In the same way, the components of the electromagnetic fields in the Cartesian coordinates can be converted to 


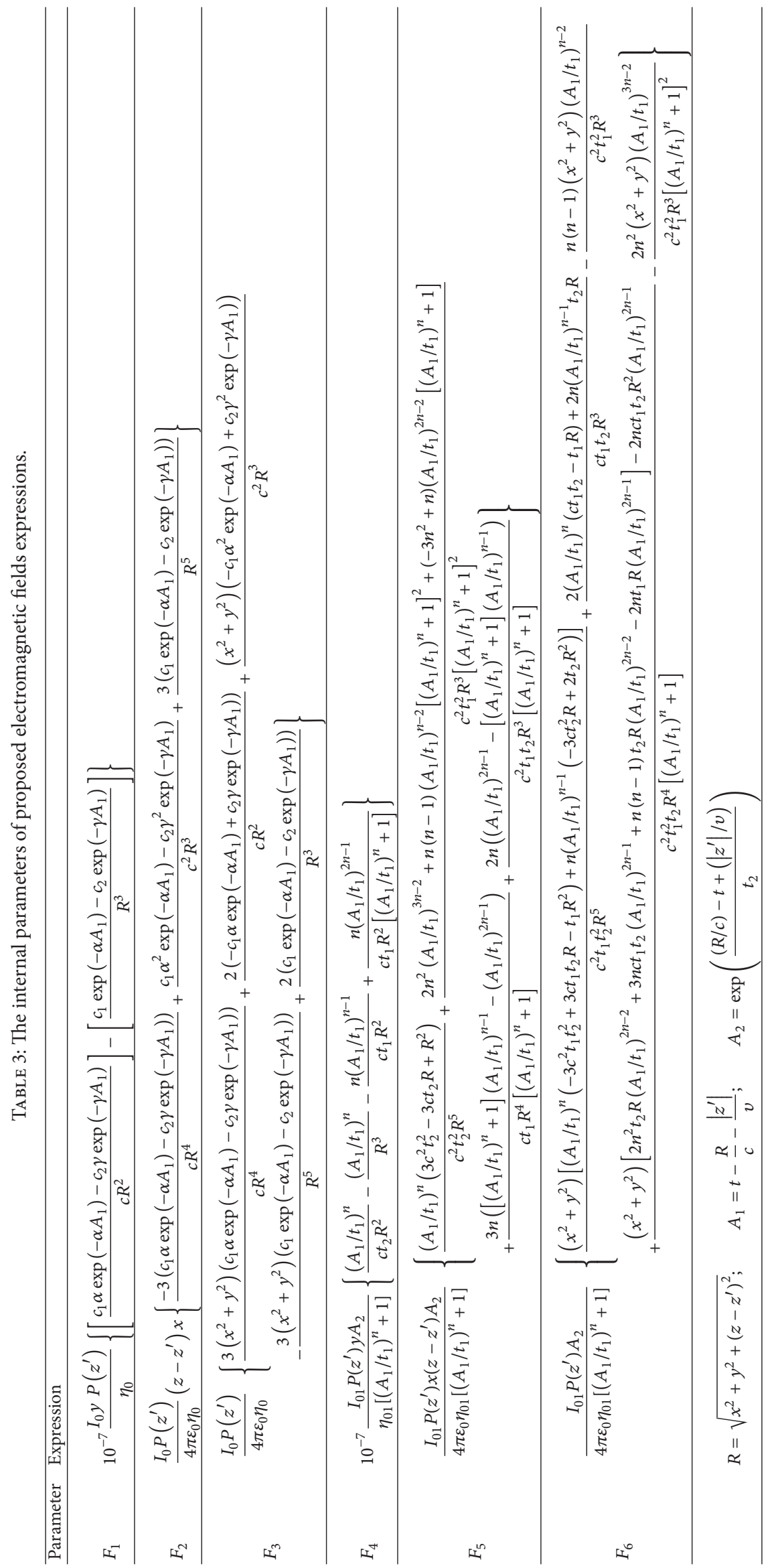


cylindrical domain using (16) and (17) for the magnetic flux density and the electric field components, respectively:

$$
\begin{aligned}
& {\left[\begin{array}{l}
\vec{B}_{r}\left(r, z, \phi, t_{n}\right) \\
\vec{B}_{\varphi}\left(r, z, \phi, t_{n}\right) \\
\vec{B}_{z}\left(r, z, \phi, t_{n}\right)
\end{array}\right]=\left[\begin{array}{ccc}
\cos \left(\frac{\pi}{2}-\phi\right) & \sin \left(\frac{\pi}{2}-\phi\right) & 0 \\
-\sin \left(\frac{\pi}{2}-\phi\right) & \cos \left(\frac{\pi}{2}-\phi\right) & 0 \\
0 & 0 & 1
\end{array}\right]} \\
& \times\left[\begin{array}{l}
\vec{B}_{x}\left(x, y, z, t_{n}\right) \\
\vec{B}_{y}\left(x, y, z, t_{n}\right) \\
\vec{B}_{z}\left(x, y, z, t_{n}\right)
\end{array}\right], \\
& {\left[\begin{array}{l}
\vec{E}_{r}\left(r, z, \phi, t_{n}\right) \\
\vec{E}_{\varphi}\left(r, z, \phi, t_{n}\right) \\
\vec{E}_{z}\left(r, z, \phi, t_{n}\right)
\end{array}\right]=\left[\begin{array}{ccc}
\cos \left(\frac{\pi}{2}-\phi\right) & \sin \left(\frac{\pi}{2}-\phi\right) & 0 \\
-\sin \left(\frac{\pi}{2}-\phi\right) & \cos \left(\frac{\pi}{2}-\phi\right) & 0 \\
0 & 0 & 1
\end{array}\right]} \\
& \times\left[\begin{array}{l}
\vec{E}_{x}\left(x, y, z, t_{n}\right) \\
\vec{E}_{y}\left(x, y, z, t_{n}\right) \\
\vec{E}_{z}\left(x, y, z, t_{n}\right)
\end{array}\right],
\end{aligned}
$$

where $\phi=\arccos \left(y / \sqrt{x^{2}+y^{2}}\right), \vec{B}_{r}(r, z, \phi, t) / \vec{E}_{r}(r, z, \phi, t)$ is the magnetic flux density/electric field at $r$-direction (horizontal), $\vec{B}_{\varphi}(r, z, \phi, t) / \vec{E}_{\varphi}(r, z, \phi, t)$ is the magnetic flux density/electric field at $\phi$-direction, and $\vec{B}_{z}(r, z, \phi, t) /$ $\vec{E}_{z}(r, z, \phi, t)$ is the magnetic flux density/electric field at $z$-direction (vertical).

\section{Result and Discussion}

This section deals with the validation of the electromagnetic fields due to lightning channel using some channel base current functions. According to the proposed method, the widely used current functions can be converted into sum of individual parts using (1) and (2). Therefore, the electromagnetic fields due to each part can be calculated by (12) and (15). Then, the values of total electromagnetic field are equal to the sum of individual components of electromagnetic field. When the MTLE model is applied as current model, the simulated magnetic flux density and the vertical electric field caused by a sum of two Heidler function as a channel base current function at an observation point with $4.6 \mathrm{~km}$ distance from lightning channel are depicted in Figures 2 and 3 , respectively. The measured magnetic flux density and vertical electric field with similar primary conditions as the ones in Figures 2 and 3 are demonstrated in Figures 4 and 5, respectively. Therefore, comparisons between the measured and simulated fields for magnetic flux density and vertical eclectic field are tabulated in Tables 4 and 5, respectively. It should be noted that the current parameters are $i_{01}=17 \mathrm{kA}$, $i_{02}=8 \mathrm{kA}, \Gamma_{11}=0.4 \times 10^{-6}, \Gamma_{12}=4 \times 10^{-6}, \Gamma_{21}=4 \times 10^{-6}$, $\Gamma_{22}=50 \times 10^{-6}, n_{1}=2, n_{2}=2, v=1 \times 10^{8}$, and $\lambda=1500$ [23].

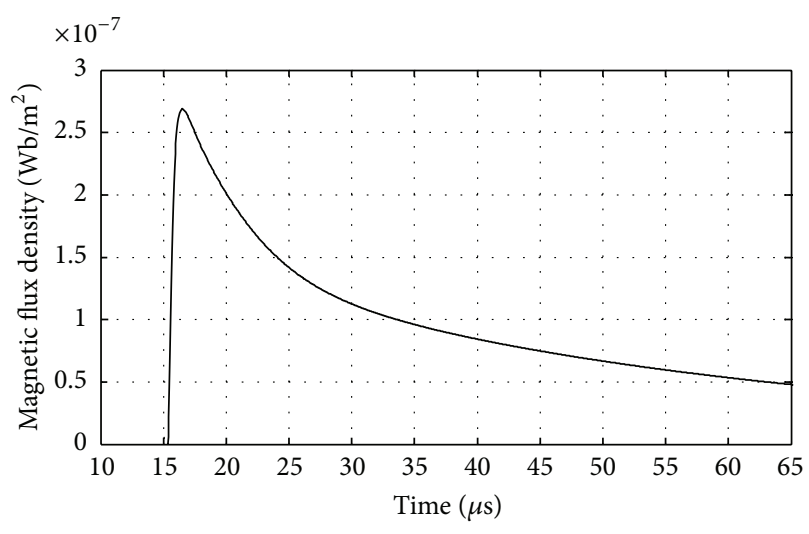

FIGURE 2: The simulated magnetic flux density using proposed method $(z=10 \mathrm{~m}, r=4.6 \mathrm{~km})$.

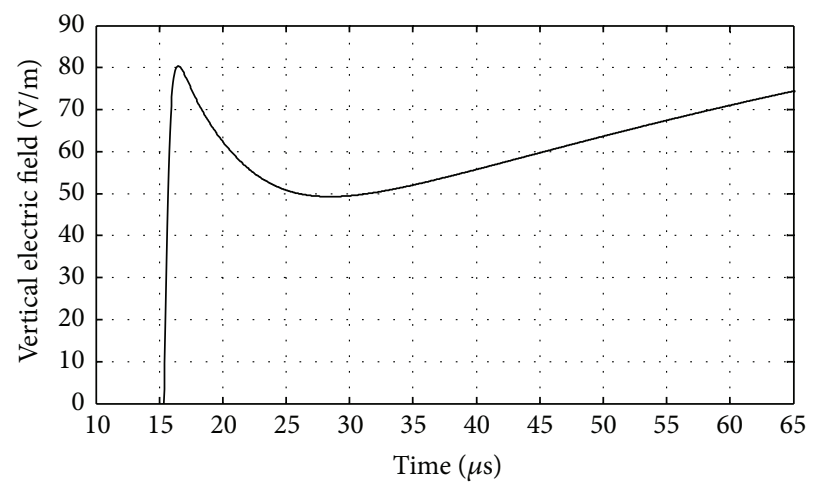

FIGURE 3: The simulated vertical electric field using proposed $\operatorname{method}(z=10 \mathrm{~m}, r=4.6 \mathrm{~km})$.

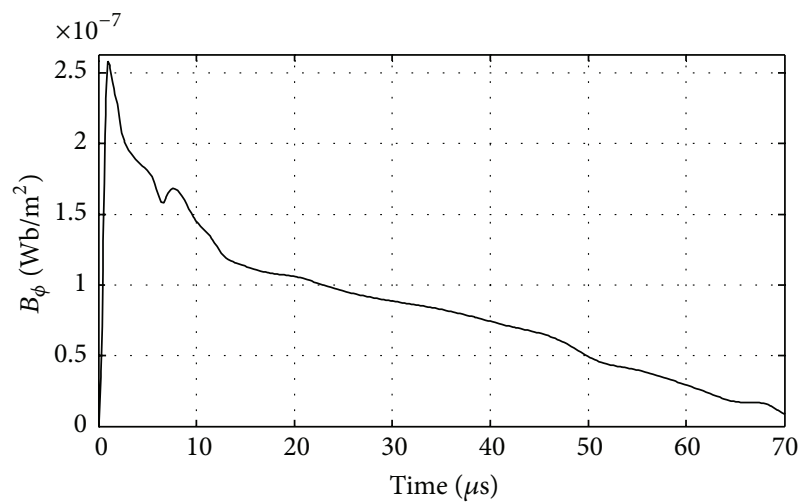

FIGURE 4: The measured magnetic flux density for an observation point $(z=10 \mathrm{~m}, r=4.6 \mathrm{~km})[23,24]$.

Additionally, the sum of two Heidler functions as a channel base current function can be expressed by the sum of two general current functions based on (2). Therefore, the total electromagnetic fields are estimated by using the proposed method and considering each current part separately. The comparison between simulated and measured fields shows the overall good agreement with experimental measurement for proposed field expressions. Similarly, the simulated fields 
TABLE 4: Numerical comparison between the simulated magnetic flux density and the corresponding measured fields from Figures 2 and 4 after subtracting initial decay time.

\begin{tabular}{lccccc}
\hline Time $(\mu \mathrm{s})$ & 2 & 5 & 8 & 10 & 15 \\
\hline$B_{\varphi}$ (measured), $\mathrm{Wb} / \mathrm{m}^{2}$ & $2.75 \times 10^{-7}$ & $2 \times 10^{-7}$ & $1.7 \times 10^{-7}$ & $1.5 \times 10^{-7}$ & $1.3 \times 10^{-7}$ \\
\hline$B_{\varphi}$ (simulated), $\mathrm{Wb} / \mathrm{m}^{2}$ & $2.7 \times 10^{-7}$ & $1.94 \times 10^{-7}$ & $1.6 \times 10^{-7}$ & $1.4 \times 10^{-7}$ & $1.25 \times 10^{-7}$ \\
\hline Percentage difference, $\%$ & 2 & 3 & 6 & 6 & 4 \\
\hline
\end{tabular}

TABle 5: Numerical comparison between the simulated vertical electric field and the corresponding measured fields from Figures 3 and 5 after subtracting initial decay time.

\begin{tabular}{lccccc}
\hline Time $(\mu \mathrm{s})$ & 3 & 10 & 15 & 20 & 25 \\
\hline$-E_{z}$ (measured), v/m & 81 & 53 & 53 & 58 & 62 \\
\hline$-E_{z}$ (simulated), v/m & 79 & 51 & 50 & 54 & 58 \\
\hline Percentage difference, $\%$ & 3 & 4 & 6 & 7 & 6 \\
\hline
\end{tabular}

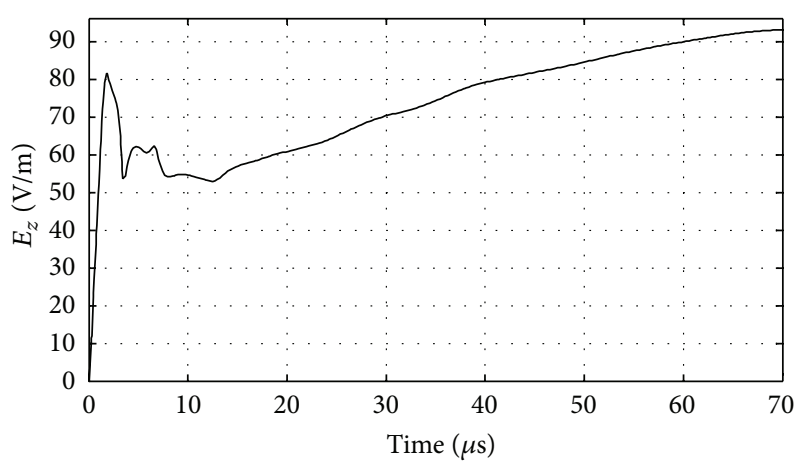

FIgURE 5: The measured vertical electric field for an observation point $(z=10 \mathrm{~m}, r=4.6 \mathrm{~km})[23,24]$.

are in accord with other previous method of calculation in $[23,24]$.

The proposed method is also validated by Nucci current function in Table 1 which is defined by the combination of (1) and (2) when the MTLL model is applied as a current model. The simulated magnetic flux density and vertical electric field are formed as in Figures 6 and 7, respectively. By the same token, Figure 8 depicts the measured vertical electric field.

In addition, the numerical comparison between the measured fields and simulated vertical fields is listed in Table 6 suggesting that the simulated field is in agreement with the corresponding measured field. Moreover, magnetic flux densities simulated using the proposed field expressions are compatible with the simulated field calculated using other methods given in the reference [5]. Note that the current parameters are $i_{01}=3.25 \mathrm{kA}, i_{02}=8.95 \mathrm{kA}, \Gamma_{11}=0.072 \times$ $10^{-6}, \Gamma_{12}=16.67 \times 10^{-6}, \Gamma_{21}=100 \times 10^{-6}, \Gamma_{22}=0.5 \times 10^{-6}$, $n_{1}=2$, and $v=1.5 \times 10^{8} \mathrm{~m} / \mathrm{s}$ [5]. The proposed expressions can directly be applied to widely used current functions in the time domain just by substituting the current and geometrical parameters in the proposed field expressions without needing to apply any extra algorithms and extra conversions (such as Fourier transform) when the realistic current functions are applied [1]. Besides, the proposed algorithm expressions can

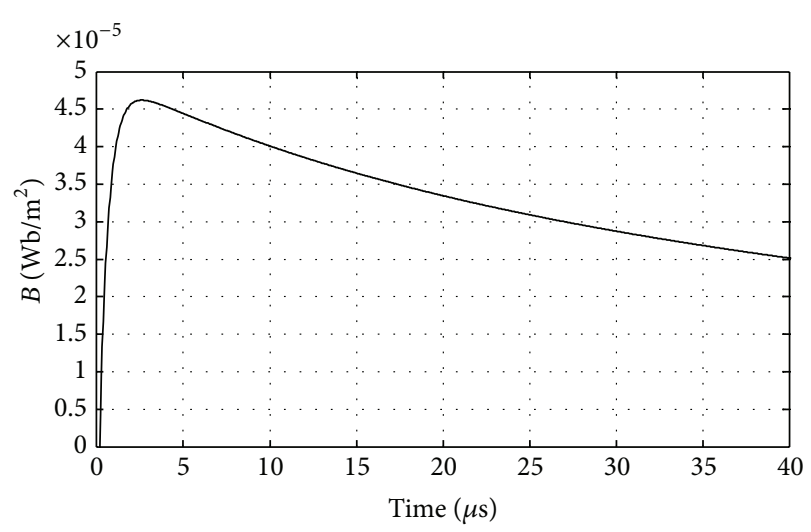

Figure 6: The simulated magnetic flux density using Nucci current function $(z=0 \mathrm{~m}, r=50 \mathrm{~m})$.

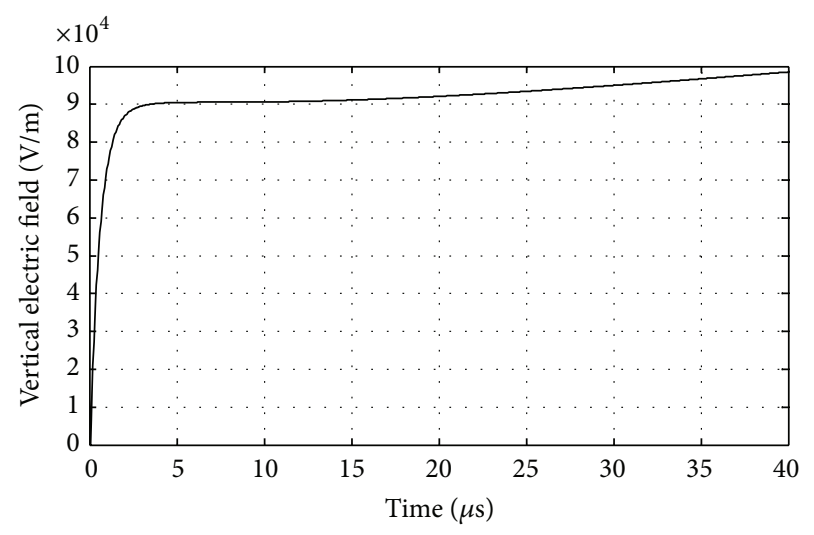

FIgURE 7: The simulated vertical electric field using Nucci current function $(z=0 \mathrm{~m}, r=15 \mathrm{~m})$.

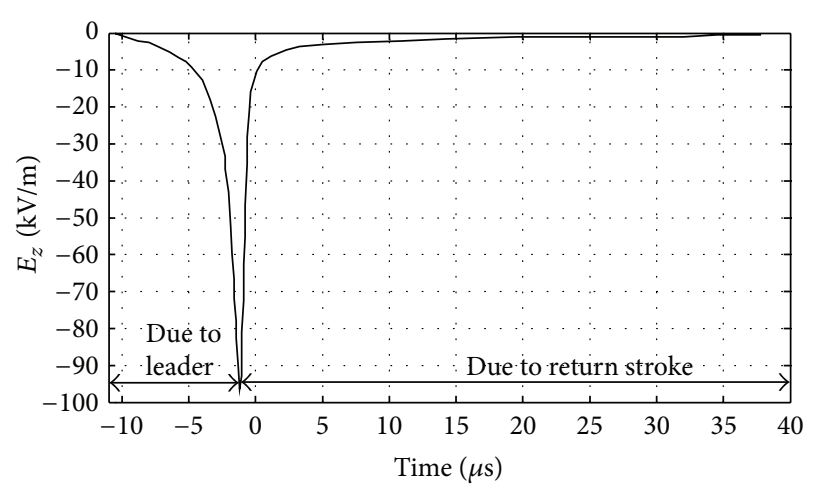

FIgURE 8: The measured vertical electric field at an observation point $(z=0 \mathrm{~m}, r=15 \mathrm{~m})[5]$. 
TABLE 6: Numerical comparison between the simulated magnetic flux density and the corresponding measured fields from Figures 7 and 8 after subtracting initial decay time.

\begin{tabular}{lcccccc}
\hline Time $(\mu \mathrm{s})$ & 5 & 10 & 15 & 20 & 25 & 30 \\
\hline$-E_{z}$ (measured), kv/m & 92 & 93 & 94.5 & 95.5 & 96 & 97.5 \\
\hline$-E_{z}$ (simulated), kv/m & 90.5 & 91 & 92 & 93.5 & 94 & 95.5 \\
\hline Percentage difference, $\%$ & 1.6 & 2.1 & 2.6 & 2 & 2 & 2 \\
\hline
\end{tabular}

support different engineering current models, provided that they follow (4).

The proposed method can corroborate most of the coupling models that compute lightning induced overvoltage (LIOV), directly in the time domain, because not only are all of the electromagnetic field components accessible but also the fundamental equations are in the Cartesian coordinates. This adds a new dimension to the development of LIOV coupling models which are restricted, in the present context, to apply a fast and direct computational block in the time domain for estimation of electromagnetic fields generated by lightning channel without needing to use extra computational stage as Fourier transform for a large number of channel base current functions and engineering current models. Likewise, the proposed field expressions can be used in the inverse procedure algorithms to evaluate lightning return stroke current using measured electromagnetic fields directly in the time domain $[8,9]$. Moreover, the proposed field expressions can be developed for the case of nonperfect ground conductivity using Cooray-Rubinstein equation [25].

Consequently, the evaluation of electromagnetic fields at different points along the power line can easily be computed with different values of $x$ or $y$ [25-28]. The accuracy of the results can be increased by changing the values of $k$ and $\Delta t$. However, the processing time will increase with such increasing of $k$. Further, the proposed field expressions can be used for close and medium distances from the lightning channel; however, some of the calculation methods in the time domain are merely confined to close distances from the lightning channel.

\section{Conclusion}

In this study, the general electromagnetic field expressions due to vertical lightning channel at an observation point are proposed directly in the time domain just by substituting of current and geometrical parameters in the proposed field expressions without needing to apply any algorithms and extra conversions. The proposed field expressions can support the widely used current functions and current models. Besides, the proposed method was validated with two return stroke current samples. The results showed that there is a good agreement between the electromagnetic fields computed by proposed method and both the measured fields and those calculated by previous simulation methods. In addition, the proposed method is applicable for both close and intermediate distances from the lightning channel and it is completely in accordance with many coupling models in evaluating the induced lightning voltage and also inverse procedure algorithms in the time domain. This would be very useful especially for the utility in assessing the lightning performance of an overhead line, particularly the distribution line.

\section{Conflict of Interests}

The authors declare that there is no conflict of interests regarding the publication of this paper.

\section{Acknowledgments}

The authors would like to thank Professor V. Cooray of Uppsala University, Sweden, who read the paper and provided valuable comments and suggestions. Universiti Putra Malaysia is also acknowledged for providing the financial support in this work.

\section{References}

[1] C. A. Nucci, "Lightning-induced voltages on overhead power lines. Part I: return stroke current models with specified channel-base current for the evaluation of the return stroke electromagnetic fields," Electra, vol. 161, pp. 75-102, 1995.

[2] V. A. Rakov, M. A. Uman, and K. J. Rambo, "A review of ten years of triggered-lightning experiments at Camp Blanding, Florida," Atmospheric Research, vol. 76, pp. 503-517, 2005.

[3] R. Thottappillil and V. Rakov, "Review of three equivalent approaches for computing electromagnetic fields from an extending lightning discharge," Journal of Lightning Research, vol. 1, pp. 90-110, 2007.

[4] R. Thottappillil and V. A. Rakov, "Distribution of charge along the lightning channel: relation to remote electric and magnetic fields and to return-stroke models," Journal of Geophysical Research D: Atmospheres, vol. 102, no. 6, Article ID 96JD03344, pp. 6987-7006, 1997.

[5] C. Yang and B. Zhou, "Calculation methods of electromagnetic fields very close to lightning," IEEE Transactions on Electromagnetic Compatibility, vol. 46, no. 1, pp. 133-141, 2004.

[6] C. Sartori and J. R. Cardoso, "Analytical-FDTD method for near LEMP calculation," IEEE Transactions on Magnetics, vol. 36, no. 4, pp. 1631-1634, 2000.

[7] M. Izadi, M. Z. A. Ab Kadir, C. Gomes, and W. F. Wan Ahmad, "An analytical second-fdtd method for evaluation of electric and magnetic fields at intermediate distances from lightning channel," Progress in Electromagnetics Research, vol. 110, pp. 329-352, 2010.

[8] A. Andreotti, D. Assante, S. Falco, and L. Verolino, "An improved procedure for the return stroke current identification," IEEE Transactions on Magnetics, vol. 41, no. 5, pp. 1872$1875,2005$.

[9] A. Ceclan, D. D. Micu, and L. Czumbil, "On a return stroke lightning identification procedure by inverse formulation and regularization," in Proceedings of the 14th Biennial IEEE Conference on Electromagnetic Field Computation (CEFC '10), IEEE, Chicago, Ill, USA, May 2010.

[10] Z. Feizhou and L. Shanghe, "A new function to represent the lightning return-stroke currents," IEEE Transactions on Electromagnetic Compatibility, vol. 44, no. 4, pp. 595-597, 2002. 
[11] M. Izadi and M. Z. A. A. Kadir, "New algorithm for evaluation of electric fields due to indirect lightning strike," Computer Modeling in Engineering and Sciences, vol. 67, no. 1, pp. 1-12, 2010.

[12] V. A. Rakov and M. A. Uman, "Review and evaluation of lightning return stroke models including some aspects of their application," IEEE Transactions on Electromagnetic Compatibility, vol. 40, no. 4, pp. 403-426, 1998.

[13] F. Delfino, R. Procopio, A. Andreotti, and L. Verolino, "Lightning return stroke current identification via field measurements," Electrical Engineering, vol. 84, no. 1, pp. 41-50, 2002.

[14] A. Andreotti, U. De Martinis, and L. Verolino, "An inverse procedure for the return stroke current identification," IEEE Transactions on Electromagnetic Compatibility, vol. 43, no. 2, pp. 155-160, 2001.

[15] A. Andreotti, F. Delfino, P. Girdinio, and L. Verolino, "A fieldbased inverse algorithm for the identification of different height lightning return strokes," COMPEL: The International Journal for Computation and Mathematics in Electrical and Electronic Engineering, vol. 20, no. 3, pp. 724-731, 2001.

[16] A. Andreotti, F. Delfino, P. Girdinio, and L. Verolino, "An identification procedure for lightning return strokes," Journal of Electrostatics, vol. 51, pp. 326-332, 2001.

[17] V. Rakov, "Lightning return stroke speed," Journal of Lightning Research, vol. 1, 2007.

[18] X. L. Zhou, "On independence, completeness of Maxwell's equations and uniqueness theorems in electromagnetics," Progress in Electromagnetics Research, vol. 64, pp. 117-134, 2006.

[19] R. Nevels and C.-S. Shin, "Lorenz, Lorentz, and the gauge," IEEE Antennas and Propagation Magazine, vol. 43, no. 3, pp. 70-72, 2001.

[20] E. Kreyszig, Advanced Engineering Mathematics, John Wiley \& Sons, New Delhi, India, 2007.

[21] M. N. O. Sadiku, "Finite difference methods," in Numerical Techniques in Electromagnetics, chapter 3, CRC Press, 2nd edition, 2001.

[22] F. Rachidi, Effects electromagnetiques de la foudre sur les lignes de transmission aerienne, modelisation et simulation [Ph.D. thesis], École Polytechnique Fédérale de Lausanne, Lausanne, Switzerland, 1991.

[23] N. M'ziou, L. Mokhnache, A. Boubakeur, and R. Kattan, "Validation of the Simpson-finite-difference time domain method for evaluating the electromagnetic field in the vicinity of the lightning channel initiated at ground level," IET Generation, Transmission and Distribution, vol. 3, no. 3, pp. 279-285, 2009.

[24] M. Paolone, C. Nucci, and F. Rachidi, "A new finite difference time domain scheme for the evaluation of lightning induced overvoltage on multiconductor overhead lines," in Proceedings of the International Conference on Power System Transients (IPST '01), pp. 596-602, 2001.

[25] C. Caligaris, F. Delfino, and R. Procopio, "Cooray-Rubinstein formula for the evaluation of lightning radial electric fields: derivation and implementation in the time domain," IEEE Transactions on Electromagnetic Compatibility, vol. 50, no. 1, pp. 194-197, 2008.

[26] M. Paolone, C. A. Nucci, E. Petrache, and F. Rachidi, "Mitigation of lightning-induced overvoltages in medium voltage distribution lines by means of periodical grounding of shielding wires and of surge arresters: modeling and experimental validation," IEEE Transactions on Power Delivery, vol. 19, no. 1, pp. 423-431, 2004.
[27] F. Rachidi, "Formulation of the field-to-transmission line coupling equations in terms of magnetic excitation field," IEEE Transactions on Electromagnetic Compatibility, vol. 35, no. 3, pp. 404-407, 1993.

[28] C. A. Nucci, "Lightning-induced voltages on overhead power lines. Part II: coupling models for the evaluation of the induced voltages," Electra, vol. 162, pp. 121-145, 1995.

[29] C. E. R. Bruce and R. H. Golde, "The lightning discharge," The Journal of the Institution of Electrical Engineers, vol. 2, p. 88, 1941.

[30] M. Uman and D. K. McLain, "Magnetic field of lightning return stroke," Journal of Geophysical Research, vol. 74, no. 28, pp. 6899-6910, 1969.

[31] R. D. Jones, "On the use of tailored return-stroke current representations to simplify the analysis of lightning effects on systems," IEEE Transactions on Electromagnetic Compatibility, vol. 19, no. 2, pp. 95-96, 1977.

[32] E. T. Pierce, "Triggered lightning and some unsuspected lightning hazards (Lightning triggered by man and lightning hazards)," ONR Naval Research Reviews, vol. 25, 1972.

[33] F. Heidler, "Analytische blitzstromfunktion zur LEMP-berechnung," in Proceedings of the 18th International Conference on Lightning Protection (ICLP '85), Munich, Germany, 1985.

[34] G. Diendorfer and M. A. Uman, "An improved return stroke model with specified channel-base current," Journal of Geophysical Research, vol. 95, no. 9, pp. 13-644, 1990.

[35] C. A. Nucci, G. Diendorfer, M. Uman, F. Rachidi, and C. Mazzetti, "Lightning return-stroke models with channel-base specified current: a review and comparison," Journal of Geophysical Research, vol. 95, no. 12, pp. 20395-20408, 1990.

[36] F. Heidler, "Travelling current source model for LEMP calculation," in Proceedings of the 6th Symposium And Technical Exhibition On Electromagnetic Compability, Zürich, Switzerland, 1985. 


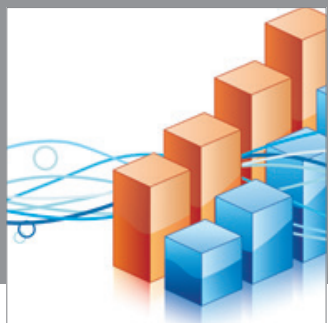

Advances in

Operations Research

mansans

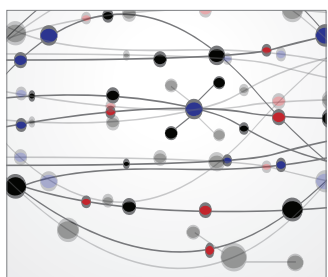

The Scientific World Journal
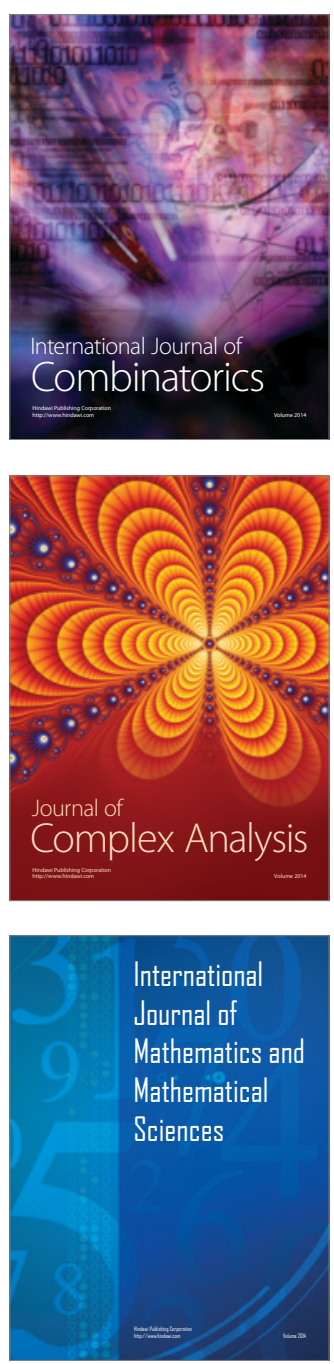
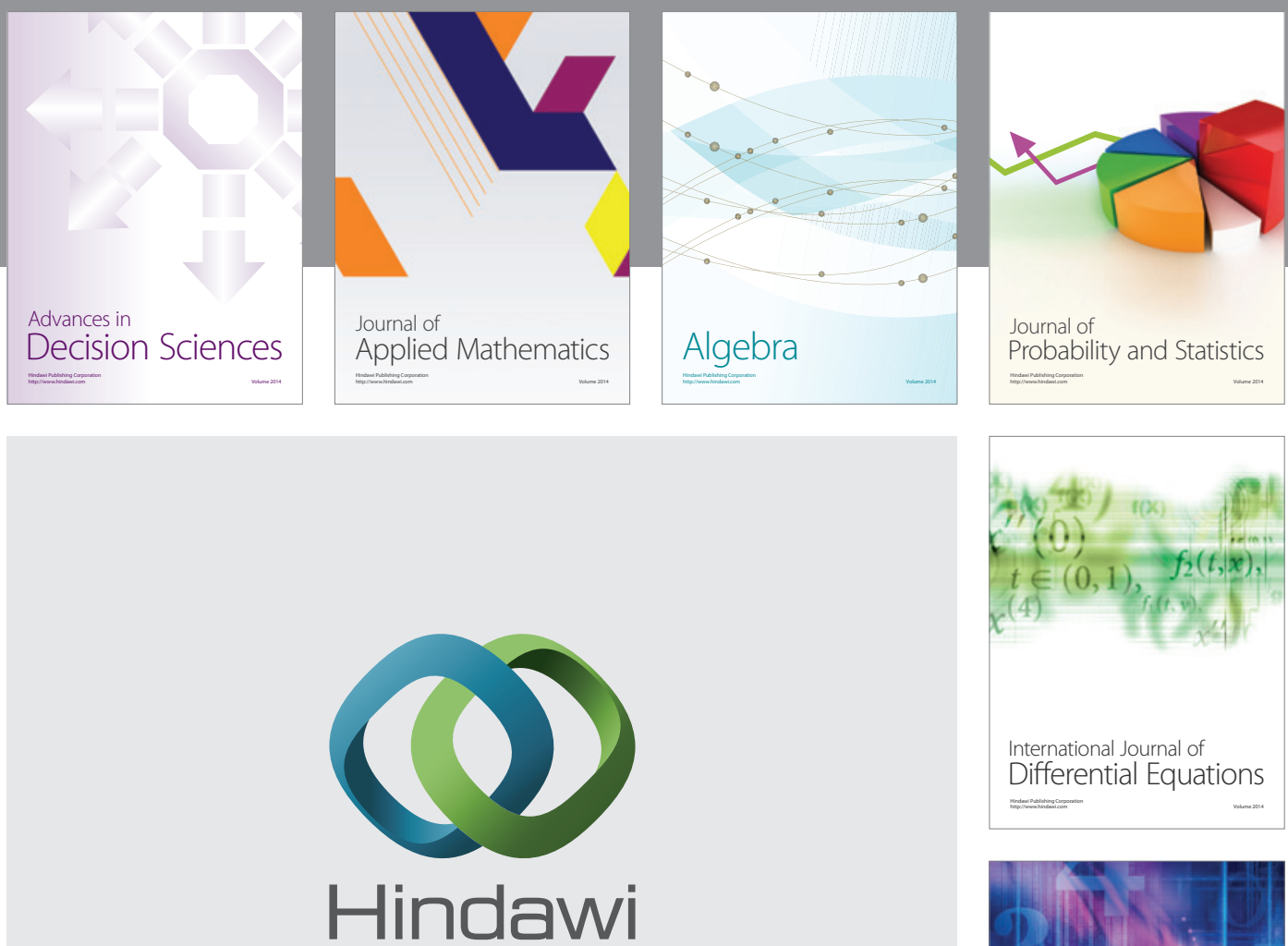

Submit your manuscripts at http://www.hindawi.com
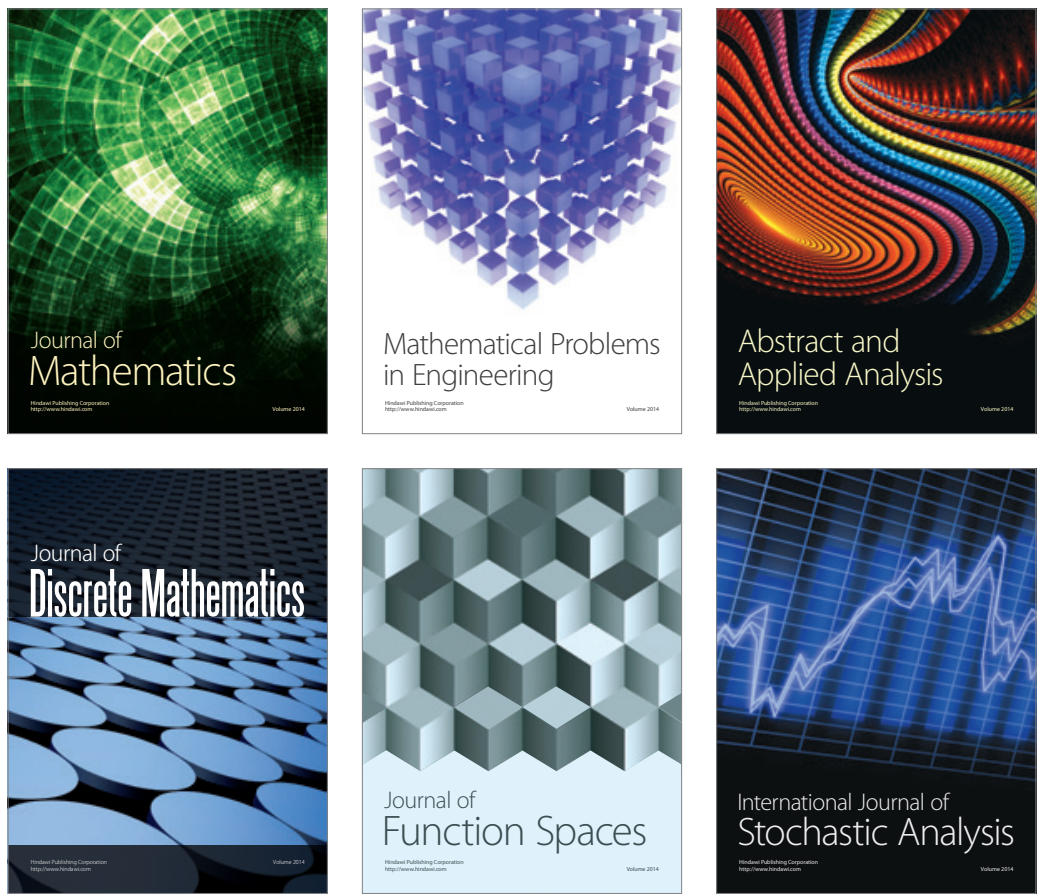

Journal of

Function Spaces

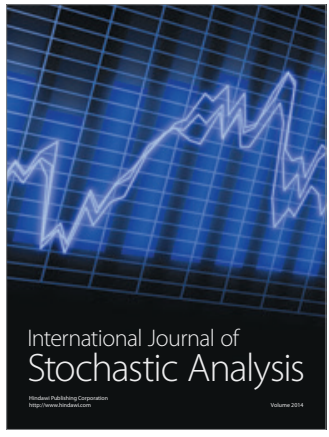

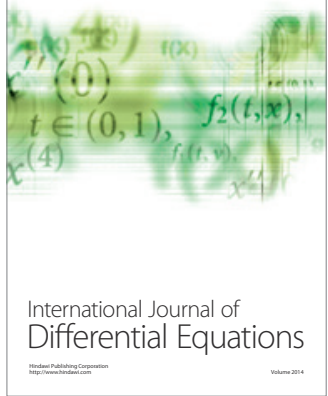
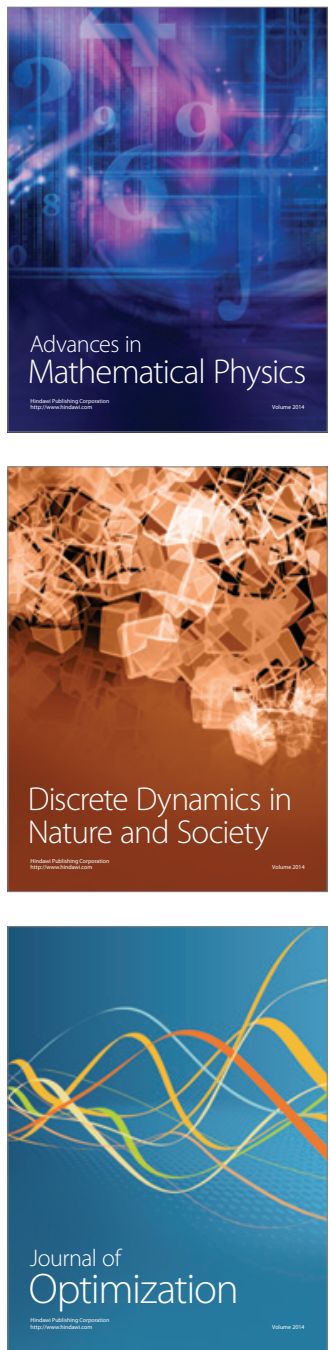